\title{
Imaginative Ecologies: Inspiring Change through the Humanities
}

\author{
Diana Villanueva-Romero, Lorraine Kerslake and \\ Carmen Flys-Junquera
}

\begin{abstract}
Perhaps that old pair of antagonists, science and poetry, can be persuaded to lie down together and be generative after all (107). WILLIAM RUECKERT
\end{abstract}

Everything is connected to everything else (35). BARRY COMMONER

This book ${ }^{1}$ has been a long-term project, one that has undergone many transformations since its origins, which date back to 2015 when a group of Spanish researchers from various fields - environmental ethics, arts and ecology, ecocriticism and literature - joined forces thanks to funding granted through a research scheme of the Spanish Ministry of Economy and Competitiveness. The title of this project, Environmental Humanities. Strategies for Ecological Empathy and the Transition Towards Sustainable Societies, ${ }^{2}$ tried to capture what was then a bold attempt in many ways, particularly in Spain. Not only did this project aspire to introduce a fairly new discipline in Spain, but it did so from a highly interdisciplinary stand by gathering a collection of perspec-

1 This work was partly supported by Proyectos I+D+I Grupos de Investigación Emergentes, Conselleria de Innovación, Universidades, Ciencia y Sociedad Digital, Generalitat Valenciana. Grant Number GV /2020/o29.

2 "Environmental Humanities. Strategies for Ecological Empathy and the Transition towards Sustainable Societies"; Subproject 2: "Stories for Change" HAR2015-67472-C2-2-R (MINECO/ FEDER). 
tives from environmental ethics, arts, and ecocriticism and by paying attention to the need to understand the contributions of visual and literary cultures in promoting social change through the activation of empathy towards the environment using imagination as a tool. Such perspective acquired momentum after the celebration of the first International Conference on Environmental Humanities held at the University of Alcalá in 2018 under the title Stories, Myths, and Arts to Envision a Change in which a variety of practitioners from these different disciplines collaborated in what was an effort to create a space for disciplinary conversation and exchange.

The inspiring premise of these initiatives was that artistic works are themselves like cultural ecosystems, ${ }^{3}$ creating awareness and interrelating ideas, visual and verbal linkages mixed with thought, values and traditions and lifestyles. In this book we take on the role of artistic works - visual cultures and literature - that promote environmental awareness through the exercise of the imagination and the analysis of these imaginative ecologies. Thus, 'imaginative ecologies' can be defined as ecologies of the mind moved by the affective connection between the writer/artist and the natureculture $s /$ he is engaged with during the creative process of acknowledging the call of the more-thanhuman in an anthropocenic world where boundaries are built between the 'us' and the 'other.' Imaginative ecologies can pave the way for creative encounters of affective knowledge between these polarities so as to make possible the type of reconciliation needed in order to overcome the perils brought about by the nonsensical detachment embedded in today's turbo-capitalism.

The "texts" represented in this book all create, in one manner or another, spaces of empathy and awareness, and foster more sustainable attitudes and practices, hoping to kindle emotion. In this sense, we are inspired by the affective turn which has taken place in the humanities and the social sciences since the mid-199o's (Athanasiou, Hantzaroula, and Yannakopoulos 5) and firmly believe in the need for literary and artistic work to be informed by "embodiment and environmental situatedness" (Weik von Mossner 6) if it wants to be generative of change. That is why this book tries to show that the response to the ecological crisis expressed in the multiplicity of phenomena that haunt

3 In "Art and the Ecosystem," Patrick Kangas also uses the word 'ecosystem' in relation with art, but his approach is focused on analyzing the artistic form of ecological models used by ecologists to represent ecosystems. Equally interesting is Pedro Alves da Veiga's formulation of "a new media art ecosystem model" in reference to his analysis of the ways in which different agents and their relationships influence the creation of a framework that can either facilitate or hinder the success of artistic projects. Here, however, the word 'ecosystem' is used in a metaphorical sense, as a way to suggest that the creative imagination is made of different forces that interact among themselves and with the outside world in producing a work of art. 
the future of planet Earth-global warming, water pollution, deforestation, biodiversity loss, etc. - does not necessarily have to come exclusively from the sciences, which always seem to opt for a detached, rational comprehension of the pressing questions of today's world. It can also arise from collaboration between arts and sciences, a methodology that, as it has already been acknowledged (Kueffer, Lässer, and Hall 2017; Kueffer et al. 2018), characterizes what has come to be known as environmental humanities. For this reason, this book gives voice to the practice of intellectuals, writers and artists from different nationalities who see themselves as participants of a global conversation on the role literature and the arts can play as facilitators of the type of social and cultural change needed in what Steffen, Crutzen and McNeill (2005) refer to as Stage 3 of the Anthropocene, a stage in which we can either continue doing business as usual or become the solution (619).

The truth is that it is not enough to simply understand the workings, for instance, of a complex process like climate change, for its rational apprehension does not mean we will commit ourselves to stopping it. What reaches our minds must necessarily move our hearts at some point in order to impel us towards the consecution of significant, long-lasting change. The scientific model is based on observation, description, testing and hypothesizing among other things. Writers and artists are experts in bringing us to our senses because they work through the muscle of empathy. They also observe and describe, test the reception of their work by their audience, and even hypothesize when they dare to create worlds of fantasy to make us see ourselves in another way, reconfigure who we are and what we represent in this world. Writers and artists are also scientists but of a subtler kind. Both groups are philosophers of the human soul trying to establish in their doings a relationship with the morethan-human world in which we all are interdependent.

This affinity between the sciences and the arts as two interlocked epistemologies is further stressed by tracing the history of the term "scientist." Stefan Collini indicates in a reprint of C. P. Snow's famous text on the cultural division into arts and sciences that "the term scientist was first proposed in 1834 along the lines of artists" (qtd. in Roberts 5). He explains that: "The lack of a single term to describe 'students of the knowledge of the material world' had bothered meetings of the British Association for the Advancement of Science in the early 1830s, at one of which 'some ingenious gentleman proposed that, by analogy with artist, they might form scientist."' (qtd. in Roberts 5 ).

The contact zone between arts and science resonates in the conversations contained in this book as the expression of a long-lasting dialogue of the inquiring human mind with nature. Perhaps our brains need more than objective knowledge in order to formulate alternatives and understand the marrow 
of the problems that affect us every day. Interestingly, environmental activism often finds a loyal ally in writers and artists all over the world. Such alliance is underlined by Donna Haraway in her work on the Chthulucene where she highlights the effectiveness of science art projects like the Crochet Coral Reef project ${ }^{4}$ to become "a case of multispecies becoming-with, a model system in which scientists, artists, ordinary members of communities, and nonhuman beings become enfolded in each other's projects, in each other's lives" (M35).

From this co-working of disciplines, it could be inferred that the meticulous and methodical work of scientists who dissect problems in order to efficiently formulate solutions is not enough. Literature and the arts in their multiple, peculiar enactments create imaginative ecologies in the sense that they translate into imaginings "the interrelationship of organisms and their environments." 5 The use of the word ecologies in the title of this volume serves to emphasize the webs of the relationships implicit in the different ways of knowing and experiencing the natural world. These ecologies are sustained by the human imagination, that potent generator of possibilities.

Thus, the term 'imaginative ecologies' is an expression that refers to the products of our imagination, those imaginings produced in our interaction with the non-human other. They are understood as the object of exploration of environmental humanists-historians, literary scholars, anthropologists, sociologists, philosophers, etc.-who perceive the need to explore the human imagination in its multifarious expression to recognize how humans negotiate their belonging to systems of naturecultures. As Brian Boyd points out, as social beings that we are, the arts appeal to our species preferences, regardless of the modifications by each local culture. Stories, he claims, "foster our ability to [ ...] imagine possible actions in the face of any eventuality" (loc. 4672). Moreover, as cognitive scientist Lisa Zunshine argues, stories provide us with knowledge and understanding as well as creating "new forms of meaning for everyday existence" (164). Thus, we as humans tend to make sense of the world and relate to it through stories. Therefore, our relationship with the natural world can be transformed thanks to the stories we create about it. Or, by applying the artistic lens, might we not be able to bring ourselves to seeing what was before unknown to us or concealed from our sight?

4 https://crochetcoralreef.org

5 The Merriam Webster Dictionary defines 'Ecology' among other things as "a branch of science concerned with the interrelationship of organisms and their environments" (Merriam Webster Dictionary. Accessed 10 July 2020). Its words are borrowed to illustrate the concept behind the expression imaginative ecologies. 
Several authors have already analysed the power of cultural artefacts, works of art and literature, to produce imaginative ecosystems where the human mind working through its empathic powers achieves a better, more profound understanding of itself in relation with the more-than-human world. William Rueckert distills his vision in his seminal article "Literature and Ecology: An Experiment in Ecocriticism" where he "[applies] ecological concepts to the reading, teaching, and writing about literature" in order to produce what he refers to as "literary ecology" (107). For him poems as well as other artwork are the "equivalent of fossil fuel (stored energy)" (Rueckert 108). Thus, any cultural artefact referred to in this book - a short story, a painting, a sculpture, an installation - can be understood in the same way. In line with Rueckert's tenets, the German ecocritic Hubert Zapf proposes "a theory of imaginative literature based on the paradigm of cultural ecology" (Loc. 129) which is a field of transdisciplinary studies where "ecology and culture, biological life science and the sciences of mind, systems theory and textual theory, natural and cultural evolution" are brought together (Loc 146). Like Rueckert, he is aware of the fact that other art forms besides literature "could equally be included in such a cultural-ecological analysis" (Zapf Loc 235) for all of them share "artistic potency" (Zapf Loc 284). That is, literature and the arts "[are] not only ergon but energia, a living force field of transformative energies which both subvert and enhance human consciousness and existence in rationalized modern societies" (Zapf Loc 306).

Thus, these imaginative discourses, these landscapes of imagination that writers and artists produce, can help us generate more sustainable forms of co-habitation. Perhaps we can learn from these creative laborers the way to disentangle our potential for fantasizing, for putting our imagination in practice. Not in vain Ursula K. Le Guin turns a passage of her book Dancing at the Edge of the World into a sheer defense of the powers of the human imagination since as she argues:

Only the imagination can get us out of the bind of the eternal present, inventing or hypothesizing or pretending or discovering a way that reason can then follow into the infinity of options, a clue through the labyrinths of choice, a golden string, the story, leading us to the freedom that is properly human, the freedom open to those whose minds can accept unreality. (45)

When this book first began its journey, nobody foresaw a global pandemic that would transform our society and the world as we knew it. Over the past months our entire life has changed shaping a future that seems anything but 
bright. The crisis that we are facing is part of a much broader problem, one deeply connected to our dysfunctional relationship with nature. Now, more than ever, imagination is key in envisioning change and rethinking the way we interact with the world around us. Despite the fact that the chapters of this book were all written and reviewed long before the pandemic, many of them address the need for our civilization to change its anthropocentric view, the necessity for a shift of perception and values which requires new narratives to inspire change. In retrospective, they read as a framework that can provide us with new approaches to nurture the web of life and rethink our relations, reconciling nature and culture, science and art and help us envision a holistic view of the world through environmental imagination.

Environmental humanities has a key role in imagining how society will change. As a transdisciplinary approach it constitutes a valuable tool of ecological awareness and ethical transformation. These chapters offer initiatives to both help understand the cultural roots of our environmental crisis and, in fostering the attitudes and skills necessary, help change the perception of humanity and its place on earth, and urge for a biocentric rethinking of human relationships to non-humans and reawaken our senses.

The book has been divided into three major sections, each addressing different aspects of our imaginative process, from different understandings of the context and the need for perceiving the problems, to the academic analysis and interpretation of creative works to the actual creative process of those imaginative discourses. In the process, we have dealt with the different discourses of various disciplines, literary studies, pedagogy, philosophy and the visual arts, yet beyond the different methodologies and perceptions, the objective is the same-how the different "texts" converge into an ecosystem striving for increased awareness and methods of reading affect and inspiring change. The book is daring in its form as it presents an imaginative mix of different academic types of inquiry, an ecology of methods such as interviews, research essays, critical and descriptive and a short story. Such multiplicity of approaches, we believe, is necessary to grasp environmental issues from a humanities-driven perspective.

Thus, the first part, Humanists in Conversation, comprises three different articles, which can be read as diverse conversations all of which communicate the need to understand the Anthropocene. They challenge us to rethink our own relationship whilst drawing on the importance of education as a key tool to communicate and understand environmental issues.

Scott Slovic's article "Environmental Humanities and the Public Intellectual" opens this section and places environmental humanities in relation to the importance of teaching. Up until now scholars in environmental humanities 
have tended to focus on small problems rather than larger and more disturbing issues. Slovic argues, very convincingly, that a shift in action is necessary and that academics need to take on a more public role in ecological literary criticism and call attention to more pressing issues. Both personal and political actions must be engaged. As Slovic urges, it is time, now more than ever, for an "absolute mobilization of our hearts and minds" and he challenges us to think differently. Drawing on the special Winter 2014 issue of ISLE: Interdisciplinary Studies in Literature and Environment, devoted to global warming and climate change, he offers various pedagogical strategies which can be applied to current environmental issues in order to put this into practice in the classroom and engage students (through academic writing and public testimony). As Slovic shows, for environmental humanities to be effective, the practice of environmental humanities scholarship and teaching must be viewed in the context of academic responsibility and accountability.

This is followed by Diana Villanueva-Romero's interview with Christof Mauch, co-director of the Rachel Carson Center for Environment and Society, in Munich. Since its foundation in 2009, the Rachel Carson Center has contributed to the development of environmental humanities and stands as one of the most prestigious institutions in the field. The conversation looks at its history and development to explore how the centre has become a pioneering model. The institution facilitates research in the field of environmental humanities and holds a series of workshops and public conferences as well as hosting a doctoral program "Environment and Society" in collaboration with the LMU Munich. As Mauch explains, key to the ethos behind the centre was the idea of bringing scholars with a common interest in the environment from different disciplines together. Through the conversation Mauch explores the difference between the terms "environmental humanities" and "environmental history" and discusses the future of environmental humanities in Europe as well as the relationship of humanities as a field with natural sciences. Like Slovic, Mauch also advocates for the importance of scholars from environmental humanities to work with natural scientists.

This first section closes with Juan Carlos Galeano's interview "El Buen Vivir is Harmony. A Conversation with Rafael Chanchari Pizuri." Galeano, who is better known for his poetry inspired by Amazonian cosmologies, looks with Rafael Chanchari Pizuri, an Amazonian philosopher and shaman, at the sophisticated narratives of indigenous Peruvian Amazon tribes and their relationship with globalization and climate change. The interview considers current environmental challenges whilst relating them to the complex knowledge systems and narratives that the Amazonians have developed from their ancestors to interpret globalization and climate change. The conversation analyses 
the notion of "El Buen Vivir," a concept which englobes the harmony between good living and happiness inviting us to reconsider our environmental crisis from a new perspective whilst looking at human relationships with nature, the river and other ecosystems.

Part two, entitled Interpreting Eco-visions, comprises articles which read as imaginative discourses to understand the Anthropocene and offer an academic analysis and interpretation of creative works. The first article "Environmental Imagination and Wonder in Beatrix Potter" by Lorraine Kerslake seeks inspiration in Rachel Carson and Lawrence Buell, drawing on the reader's ability to experience a sense of connection with the environment and looks at the role that children's literature can play in imagining a more sustainable society and the importance of instilling a sense of wonder to the natural world in children. The chapter explains the close and necessary relationship between science and literature in the life and work of Beatrix Potter and how that close tie brings about a more realistic, non-sentimentalized awareness of nature for children. Through Potter's imagination and art, literature and drawings, children are both engaged with but also made aware of the not always peaceful cohabitation between species in the ecosystem.

This is followed by Chris Fremantle and Anne Douglas's article "Foregrounding Ecosystems: Thinking with the Work of Helen Mayer Harrison and Newton Harrison" which draws on The Serpentine Lattice (1993) and literary and visual devices such as ethnopoetics, presenting us with an alternative way of understanding the world and our existence, fundamental for the wellbeing of the web of life and ourselves. The chapter highlights the complexity of the Harrisons's artwork, combining visual arts, poetry, economics, ecology and politics and how this artistic imagination can shock audiences into striking realization that in turn can effect change.

Irene Sanz-Alonso's chapter "New Worlds Beyond Reality: Imagined Futures in Laura Gallego's Las Hijas de Tara" explores the values of alternative worlds and the societies portrayed in literary genres such as fantasy and science fiction as an alternative example of cohabitation. Sanz focuses on well-known Laura Gallego's novel Las hijas de Tara [Tara's Daughters], another work aimed at young adults. The writer uses her imaginative and pedagogical capacity to illustrate the negative consequences of an extreme nature/ culture dualism. She creates an alternative futuristic world where nature and technology are at loggerheads with each other: both worlds are in continuous war against each other and the inhabitants of each are completely ignorant of the other. The journey of two girls from opposing worlds leads them to dispel their prejudices, understand and help each other, pointing to a lesson of tolerance and more balanced attitudes. 
This is followed by Imelda Martín's chapter, “Simon Ortiz's Narratives and Joy Harjo's Poems: Towards Regenerative Societies and New Worlds" which uses the works of Ortiz and Harjo as windows which open to new possibilities and focus on the recovery of a "storytelling" tradition, representing an escape towards a transition of creating regenerative communities and new worlds. This chapter highlights how the stories and poems by Ortiz and Harjo draw new maps and paths in various directions in order to regenerate a harmonious balance and dialogic interspecies ethics. The tales shift from traditional Native American perspectives to the recreation of more sustainable and respectful attitudes which gather the old together with the new.

The section closes with Barbara Fluxá's piece "When Matter Takes a Position: Post-anthropocentric Landscapes in Contemporary Art," which advocates contemporary art as a transdisciplinary approach and offers a new cultural paradigm as an alternative to our systemic global crisis and the displacement of humanity. Fluxá illustrates how the artistic imagination, coupled with technology and scientific models, creates or recreates geological, natural and technological processes which have or could alter this Earth. She focuses on numerous artists and installations which in different manners recreate geological processes. The recreations clearly affect the viewers who, at times, unwittingly become performers by interacting physically with these installations, and are propelled into an awareness of these processes and their implications. The result goes beyond the simple representation of nature to look at artists in collaboration with those who work in the study of the solid earth and soil sciences to propose post-anthropocentric landscapes.

The last part, Inspiring Change, pays special attention to the creative process of imaginative discourses revolving around the idea that cultivating an awareness of the land may help to construct communities that, with time, will interact with their surroundings in a more sustainable way. It opens with artist Carma Casulá's contribution, "Sense of Place as an Enhancer of Empathy and Ecological Consciousness in the Baix Llobregat" whose site-specific work looks at landscape and the emergence of an ecological conscience among the inhabitants of the Baix Llobregat, an ambivalent space where conservation of spaces of significant natural, touristic and agricultural tradition co-exist with environmental degradation derived from intense industrial exploitation. As a photographer, Casulá's project is aimed at making this situation visible by creating a photographic series which she refers to as "forming a Memory Bank of Farmers in Spain." The collection is organized around two goals: first, offering a Physical Map of the area, and second, creating an Affection and a Connectivity Map based on the results of her field work with the local people through which she tried to understand the maze of relations that underlies 
their attachment to the place where they have traditionally lived and work. Hence, relationality becomes the organizing trope of a chapter where the author also voices her criticism of contemporary systems of living marked by a "disproportionate disaffection" and impels the reader to "[activate] biocentric attitudes."

This is followed by Carmen Flys and Beatriz Lindo's interview with the earth-based spiritual writer and activist Starhawk, aptly entitled "Building Stories to Change the World." The interview draws on Starhawk's novels and looks at the role of using narratives to envision change and reinvent new worlds through stories. This conversation shares with the previous one an attention to community, although of an experimental kind given the impact of Starhawk's novel The Fifth Sacred Thing (1993) where the artist-activist explores new ways of being in the world by describing what it would be like to live in a place ruled by norms inspired by "usefulness, beauty, sustainability, nourishing for the earth (or not damaging) and nourishing for the soul." Starhawk emphasizes the importance cultural and social tools have in addressing pressing issues of environmental importance such as climate change. She defends the power of imagination and ritual to instil change and offers a hopeful perspective on the potentiality of humans to regenerate themselves into better coparticipants of planet Earth.

In line with this message, Elena Sánchez-Vizcaino and Lucía Loren's article "Eco-interactions: Art and Community" offers insight to answering the question of how the arts can contribute to creating a more sustainable society. In doing so, Elena Sánchez-Vizcaino analyses Lucía Loren's work and her experience and interaction with environmental art through local communities. Loren's interventions, which she likes to refer to as "interactions," always invite local people to contribute with their knowledge and sensitivity to the place. Such is the case of Al hilo del paisaje / Landscape Thread (2007) done in collaboration with the people of Santa Lucía de Ocón, La Rioja (Spain). This is so because Loren, as Sánchez-Vizcaino explains, conceives her work as the result of a collaboration with the inhabitants of the place where her art will be integrated in its landscape. In her participatory model of art creation, Loren finds a potential to provoke an emotional reaction as well as a consciousness-raising. This gives her projects the potential to "[communicate] what is not visible to reason" and in so doing to serve as an inspiration for the future.

Last, but not least, the book closes with an epilogue in which José Manuel Marrero-Henríquez offers in "Chickens like Celebrities" a short story which takes place during a transatlantic flight when the protagonist, whilst contemplating a lunch menu, suddenly decides to become vegetarian for the wellbeing of the planet. The short story itself is an act of the author's imagination 
but it also deals with the imagination of the protagonist and how this inspires a personal decision to change. Marrero-Henríquez's short story meaningfully embodies the role that imagination can play in producing new responses to daily activities, such as eating meat, which may represent a more thoughtful appraisal of the role to play by humans in the world.

In the fields of literature and the arts, the importance of imagination to engage the reader and viewer and contribute towards change is more pertinent now than ever. Changing our view of humans' place in the world could actually save our planet. Imagination is perhaps the most important tool we have to do so. Not only can it engage us, but it can also make us aware of the impact of our actions and thus help to change our attitudes. The following chapters, from a variety of fields inherent to environmental humanities, therefore share an inherent conviction that imagination and the humanities can play a significant role in heightening environmental awareness and inspiring changing attitudes to promote transformation. As editors we hope these creative discourses may provide readers with ideas to inspire resilience towards the global environmental crisis that we are now fully immersed in. It is never too late to commit oneself to rethinking our relationship with nature and aspire to the type of harmony one of the contributors to this book, Rafael Chanchari Pizuri, describes from the last remnants of the Amazonia. Perhaps one day, in the not-too-distant future, the notion of "el buen vivir" will become a reality. Until that day comes, we will have to make do with finding hope and seeking ways to imagine change such as those suggested in this book.

\section{Works Cited}

Alves da Veiga, Pedro. "Towards a New Media Art Ecosystem Model." September 2005. PDF file. ResearchGate, doi:10.13140/RG.2.1.3551.5369. Accessed 16 April 2021.

Athanasiou, Athena, Pothiti Hantzaroula, and Kostas Yannakopoulos. "Towards a New Epistemology: The 'Affective Turn." Historein 8 (2008): 5-16.

Boyd, Brian. On the Origin of Stories: Evolution, Cognition and Fiction. Belknap Press, 2009. Kindle edition.

Commoner, Barry. The Closing Circle: Nature, Man, and Technology. 1971. Courier Dover Publications, 2020.

"Ecologies." Merriam-Webster Online Dictionary. https://www.merriam-webster.com/ dictionary/ecology. Accessed 20 July 2020.

Haraway, Donna J. "Symbiogenesis, Sympoiesis, and Art Science Activisms for Staying with the Trouble." Arts of Living on a Damaged Planet: Ghosts and Monsters of the Anthropocene, edited by Anna L. Tsing et al., U of Minnesota P, 2017, pp. M25-M5o. 
Kangas, Patrick. "Art and the Ecosystem." The American Biology Teacher, vol. 6o, no.1, 1998, pp. 20-26.

Kueffer, Christoph, et al. "Applying the Environmental Humanities." GAIA-Ecological Perspectives for Science and Society, vol. 27, no. 2, 2018, pp. 254-56.

Kueffer, Christoph, Katharina Thelen Lässer, and Marcus Hall. "Applying the Environmental Humanities: Ten Steps for Action and Implementation." GAIA, 2017, pp. $254-56$.

Le Guin, Ursula K. Dancing at the Edge of the World:Thoughts on Words, Women, Places. Open Road+ Grove/Atlantic, 2017.

Roberts, Adam. The History of Science Fiction. Palgrave Macmillan, 2016.

Rueckert, William. "Literature and Ecology: An Experiment in Ecocriticism." 1978. The Ecocriticism Reader, edited by Harold Fromm and Cheryl Glotfelty, U of Georgia P, 1996. 105-23.

Steffen, Will, Paul J. Crutzen, and John R. McNeill. "The Anthropocene: Are Humans Now Overwhelming the Great Forces of Nature?" AMBIO: AJournal of the Human Environment, vol.36, no.8, 2007, pp. 614-21.

Weik von Mossner, Alexa. Affective Ecologies: Empathy, Emotion, and Environmental Narrative. Ohio State UP, 2017.

Wertheim, Margaret, and Christine Wertheim. Crochet Coral Reef. The Institute for Figuring. https://crochetcoralreef.org Accessed 20 July 2020.

Zapf, Hubert. Literature as Cultural Ecology: Sustainable Texts. Bloomsbury, 2016. Kindle edition.

Zunshine, Lisa. Why We Read Fiction: Theory of Mind and the Novel. Ohio State UP, 2006. Kindle edition. 